Orbis Tertius, vol. XXIV, $\mathrm{n}^{\circ}$ 30, e134, noviembre 2019-abril 2020. ISSN 1851-7811

Universidad Nacional de La Plata

Facultad de Humanidades y Ciencias de la Educación

Centro de Estudios deTeoría y Crítica Literaria

\title{
María Celia Vázquez, Victoria Ocampo, cronista outsider. Rosario, Beatriz Viterbo, 2019, Ensayos Críticos 250 páginas
}

Si escribir un libro se parece - dice María Celia Vázquez - a la ardua tarea de cruzar un río, la experiencia de escribir un libro sobre una figurita repetida y difícil y publicarlo en 2019 se aproxima más a la metáfora del cruce de océanos entre continentes. Una imagen que hace eco en esta escritora de aquí pero también de allá, a la que se calificó, para bien y/o para mal, como una suerte de "aduana cultural" por sus importaciones y exportaciones culturales a través de Sur, como una "Gioconda de Las Pampas”, quizá por esa capacidad de "ver" propia del ser autóctono, por tomar dos casos que pudieron repercutir discusiones resonantes de la época sobre nacionalismo y cosmopolitismo.

Probablemente llena de vacilaciones ante una labor crítica de tantos desafíos, Vázquez opta por operaciones críticas convincentes que hacen de este libro una contribución original en la vasta tradición de lecturas construidas sobre Victoria Ocampo en momentos fundamentales del siglo XX a nivel local e internacional: el sufragismo y los feminismos pioneros, la pregunta por el ser nacional en la ensayística de los '30, el colaboracionismo y la política internacional de los '40, el populismo cultural asociado al peronismo de los '50 y' 60.

Si las clasificaciones consolidadas ya habían resultado problemáticas para ubicar a Victoria en su momento, Vázquez elige hoy una zona de fuga y pone su atención en un volumen de textos raros que bordean las intersecciones entre literatura y periodismo, publicados en diferentes medios y a lo largo de cuatro décadas (1935-1977), que la propia Victoria aunó como libro bajo el título de Testimonios. Pero, además, Vázquez se interesa menos en definiciones obsoletas para situar a Victoria que en su voluntad de intervención cultural y política en la escena pública. De este modo, la autora propone leer sus testimonios como textos independientes tanto de su autobiografía (blanco de preferencia de la crítica en general) como de los mitos de autora que fue forjando la biografía intelectual y política de Victoria Ocampo, y para ello apela a la especificidad de estos testimonios como textualidades de fuerte intervención.

Victoria como una "outsider", como una "fuera de foco" en el proceso de autonomización literaria y consolidación de la profesionalización femenina mediante la escritura. Ahora bien, Ocampo no necesita ganarse la vida y menos aún mediante la práctica del periodismo, como es el caso real de Roberto Arlt y Alfonsina Storni, por tomar un varón y una mujer contemporáneos, para quienes el periodismo es un oficio remunerado, sin el cual directamente se caerian del sistema, y en menor medida un posible espaldarazo a sus expresiones literarias. En lugar de escribir novelas o de ingresar a la vida literaria mediante la prensa, que eran itinerarios comunes de formación de escritores y escritoras, Ocampo evidencia otra vez su condición outsider. No sólo construye un artilugio retórico por el cual se autodefine inválida por carecer de imaginación para escribir novelas sino que escoge géneros por entonces considerados "menores" en el amplio dominio de la literatura para validar mediante la escritura, y así dar fe de lo que ha visto y ha oído.

Ocampo se mueve con la impunidad que da la seguridad de clase entre un amplio repertorio de temas. Pero la cronista en vez de salir desesperada a buscar esos temas para cumplir con los tiempos del periodismo (como 
tan bien lo han retratado Roberto Arlt o Sara Gallardo), se planta como una testigo del mundo moderno del que es contemporánea y forja un "yo privado" que demuestra una férrea voluntad de intervención mediante una mirada personal en la arena pública.

¿Cómo leer desde un prisma novedoso todo ese archivo que la propia Ocampo desempolva para hacerlo libro? Además de todas las estrategias antes expuestas, Vázquez diseña una metodología de acercamiento que los aglutina según tres grandes categorías que atraviesan tanto la figura como la contemporaneidad de Victoria: "Espacios", "Litigios" y "Duelos".

En este libro se leen los testimonios "pampeanos" de fines de los años '20 a partir de conceptos de Lotman y Didi-Huberman. El espacio nacional por excelencia se percibiría menos como evidencia que como representación y vaciamiento de la forma. Vázquez identifica cómo Ocampo instala, por un lado, la diferencia sustancial entre el acto de "ver" más allá de la pura planicie y la identidad manifiesta que llevan adelante los autóctonos como ella, frente al hecho tautológico de "mirar" que practican quienes vienen de afuera. Y, por otro, una interrogación sobre la línea interpretativa sobre el imaginario nacional que impusieron quienes ella llama los “quirorománticos" (desde Sarmiento a Ezequiel Martínez Estrada) al interpretar la pampa como la palma de la mano de los relatos fundacionales. Ocampo se ocupará de auscultar los designios de la nación como artefactos complejos de diferentes matices para lo que hará primar su individualidad en el vínculo con paisajes "privatizados" por sus modos de ver: cuanto más vea la pampa y el río, más se enriquecerán bajo los ojos de su hambre americana.

$\mathrm{Al}$ mismo tiempo, interesa resaltar cómo la ocasión del adiós a las amigas y los amigos instala, según la lectura de Vázquez, una política de la amistad que propulsa siempre un pronunciamiento político. Por caso, el obituario que le dedica a la pedagoga española feminista María de Maetzu, le permite a Victoria tomar la palabra para anteponer la cuestión feminista y su visión del destino político de las mujeres al dolor por la ausencia de la amiga. Por supuesto que Ocampo posee una trayectoria de intervenciones activas en el feminismo - su participación orgánica en la presidencia de la Unión Argentina de Mujeres entre 1936 y 1938 - que sostiene el uso político que hace del obituario. En lugar de regodearse en el llanto y el lamento por el ser querido - acaso los comportamientos esperables y permitidos para una mujer- Ocampo realiza un homenaje feminista mediante el cual se pronuncia políticamente a favor de la lucha compartida y heredada de su amiga: el despertar de la conciencia cívica y la educación de las mujeres. Pero en sus obituarios, Victoria también dejará clara su posición antiperonista, pese a que para ello deba oponerse a la campaña del sufragismo de los años '40, a la que entiende menos como una ampliación de derechos para las mujeres que ya venían desde años exigiéndolos, que como una iniciativa demagógica del peronismo. Es sabido que Ocampo se resiste a las iniciativas sufragistas que además coronaban a Eva Perón, mediada por la voz masculina de su compañero, como estandarte de una conquista que así aparecía deshistorizada y desmemoriada.

¿Dónde quedarían las pioneras de las luchas femeninas y las batallas dadas por Julieta Lanteri, Carolina Muzzilli, Alfonsina Storni, e incluso por la polémica Salvadora Medina Onrubia? ¿Dónde quedaría el diálogo, (que entiende como una marca de género), entre mujeres que se turnan para tomar la palabra frente al esquema monológico de la hegemonía masculina que representaba Juan Domingo Perón incluso en sus políticas de ampliación de derechos que no hacían más que dejar a las mujeres como escuchas pasivas?

El legado y la misión que la amiga española dejara en Victoria al morir son retomados, cuando quien muere es Victoria, por María Oddone y María Elena Walsh, dos referentes del feminismo de los '70 y '80. Se sella así una política de sororidades entre esas mujeres unidas por una cadena testamentaria, cuyos pactos se enuncian y comunican siempre en plural.

Este libro de María Celia Vázquez diseña no sólo nuevos itinerarios para abordar la producción y la figura de la transitadísima Victoria Ocampo sino que propone un gesto innovador: instalar desde ella genealogías hacia delante, hacia una zona futura.

Victoria Ocampo, cronista outsider constituye un ensayo erudito y bien escrito que abre nuevos caminos para abordar zonas inexploradas de la producción de Victoria Ocampo, como estos testimonios que se rebelan 
a los encorsetamientos y que recolocan a la escritora de la élite, a la periodista sin sueldo, a la que supo francés antes que castellano, a la fundadora de Sur, a la hermana de Silvina, a la amiga de Bioy y Borges, a la feminista que se le opone a Eva, a la que se siente menos en el Viejo Mundo y sale con toda la artillería contra los nacionalistas, a la que expía al amigo amante colaboracionista y a la que se declara antifascista, siempre en posiciones de riesgo, de incomodidad, inestabilidad y hasta de incorrección política. 